\title{
Mulheres na Física: experiências de docentes e discentes na educação superior
}

\author{
Maria Eulina Pessoa de Carvalho**
}

\begin{abstract}
Resumo
O texto se baseia em pesquisa financiada pelo CNPq interessada nas percepções e experiências de docentes $e$ discentes mulheres sobre as relações de gênero na vida acadêmica em campos tradicionalmente masculinos, fazendo o recorte da Física. O campo de investigação é uma universidade federal nordestina e o procedimento metodológico envolveu entrevistas, a partir do mapeamento da distribuição de docentes e discentes por sexo. Os resultados mostram dificuldades de mulheres, como professoras e alunas, para se incluírem no campo.
\end{abstract}

Palavras-chave: Gênero, Educação Superior, Física, Professoras, Alunas.

\footnotetext{
* Recebido em 24 de dezembro de 2018, aceito em 23 de julho de 2020.

** Professora Titular da Universidade Federal da Paraíba (UFPB), João Pessoa, PB, Brasil. mepcarv@gmail.com / https://orcid.org/0000-0002-2947-5814. 


\section{Introdução}

Este texto sintetiza resultados de pesquisa financiada pelo CNPq (Carvalho, 2017; 2012) ${ }^{1}$ interessada nas percepções e experiências de docentes e discentes mulheres sobre as relações de gênero na vida acadêmica em campos tradicionalmente masculinos. Faz o recorte da Física, uma das disciplinas mais masculinas da área de Ciências Naturais, Tecnologia, Engenharias e Matemática (CTEM), explorando as seguintes questões: Como elas descrevem a cultura acadêmica de seu departamento ou curso, práticas e valores, relações interpessoais e profissionais, facilidades $e$ dificuldades de inclusão? É possível traçar perfis de mulheres incluídas nesse campo como docentes e discentes, e padrões de in(ex)clusão, a partir do conhecimento de características individuais, projetos profissionais, trajetórias, padrões de produtividade e práticas culturais/institucionais?

O campo de investigação é uma universidade federal nordestina e o procedimento metodológico envolveu mapeamento da distribuição de docentes e discentes por sexo, e entrevistas face a face e/ou por internet. A abordagem parte de dados quantitativos para descrever o problema, mas é sobretudo qualitativa, fundada no paradigma interpretativo e no enfoque teórico da pesquisa biográfico-narrativa (Andrade, 2012; Kelchtermans, 1994), no caso das docentes.

A coleta de dados encontrou dificuldades. Primeiro, pela indisponibilidade de dados desagregados por sexo sobre docentes e discentes na instituição. Segundo, pela falta de tempo dos sujeitos para a realização das entrevistas. Com as professoras, as entrevistas foram iniciadas em 2011 (Carvalho, 2012) e complementadas em 2015, em pesquisa de doutorado (Silva, 2017); com as alunas de graduação e pós-graduação foram realizadas em pesquisa de mestrado em 2016 (Amorim, 2017).

A análise dos dados buscou identificar percepções de desigualdade de gênero nos relatos colhidos acerca do significado de acontecimentos e experiências que integram a vivência passada $e$ atual da formação e/ou do exercício profissional. No caso das docentes, as entrevistas foram inspiradas no modelo do ciclo de entrevistas de Kelchtermans (1994), realizadas em diferentes momentos, gravadas, transcritas, organizadas em biografias docentes e devolvidas às entrevistadas.

$\mathrm{O}$ texto subsequente está organizado em duas seções. A primeira descreve a raridade de mulheres na Física na universidade pesquisada, como docentes e discentes. A segunda apresenta aspectos da cultura acadêmica do departamento e curso, segundo as alunas e professoras entrevistadas: práticas e valores, relações interpessoais e profissionais, facilidades ou dificuldades de inclusão; e delineia um padrão de in(ex)clusão de mulheres na Física a partir de suas trajetórias em meio às práticas culturais/institucionais vigentes, que configuram sua raridade $e$ subalternidade. $\mathrm{A}$ conclusão sintetiza a problemática brasileira atual e aponta desafios de superação.

\section{Tão poucas!}

Como se sabe, a atual vantagem numérica das mulheres em matrículas em cursos superiores, no Brasil e em países americanos e europeus, entre outros, não se apresenta na área de CTEM, onde a presença delas continua muito reduzida. Ademais, como aponta a literatura e confirma a experiência local, existe evasão e atraso na conclusão de curso, que afeta mais as alunas do que os alunos. Esse fenômeno tem sido denominado de vazamento (leaky pipeline) ou filtro de gênero (Blickenstaff, 2005) e está relacionado com a cultura e pedagogia dura do campo. Com poucas alunas, há poucas professoras e falta de modelos femininos, o que constitui um ciclo vicioso.

Nesse contexto, destaca-se a Física como uma das disciplinas em que permanece a subrepresentação das mulheres no mundo e no Brasil (Skibba, 2016; Agrello; Garg, 2009). Como vem evoluindo a distribuição de mulheres em um departamento (docentes) e um curso (discentes) de Física?

O Departamento de Física da instituição de ensino superior (IES) pesquisada permaneceu em toda a sua história com duas mulheres em seu corpo docente. Quando uma das docentes se aposentou, na década de 1990, ingressou outra. Os docentes homens eram 27 em 2009, 30 em

\footnotetext{
${ }^{1}$ A pesquisa foi autorizada pelo Conselho de Ética da universidade, pelo Departamento de Física e individualmente pelas participantes, cujos nomes são omitidos.
} 
2012, 32 em 2014, portanto cresceu o número de homens, mas não de mulheres no corpo docente. Até 2016 , as duas professoras perfaziam $5,88 \%$ do corpo docente do departamento. No início de 2017, uma delas se aposentou e a outra se transferiu, portanto, o departamento só tem hoje docentes do sexo masculino - 33 em 2018 (informações capturadas no Sigaa da IES).

O curso de pós-graduação em Física (mestrado e doutorado) contava em 2014 com 23 docentes, sendo duas mulheres, uma do departamento e outra visitante; em 2018 são 28 professores (26 permanentes) e uma professora colaboradora, já que a professora do departamento se foi. O corpo discente contava, em 2014, com 4 mestrandas em 26 e 7 doutorandas em 63; em 2017 eram 3 mestrandas em 16; e 10 doutorandas em 59. Em 2018 são 6 mestrandas e 13 mestrandos; 10 doutorandas e 47 doutorandos (informações capturadas no Sigaa da IES).

No segundo semestre de 2017, as alunas de graduação em Física (Bacharelado e Licenciatura) eram 55 ou 17,5\% do corpo discente. De acordo com o gráfico 1, em um histórico de 47 anos, o alunado do curso apresenta uma média de $85 \%$ de homens e $15 \%$ de mulheres. $\mathrm{O}$ cenário mostra uma taxa insignificante de aumento de mulheres, de apenas $0,01 \%$ ao ano. Permanecendo tal tendência, apenas no ano 2.367 haveria a desejável paridade de sexo no curso de graduação em Física.

Nesse cenário, a naturalização do gendramento do campo é tal que um coordenador da graduação, entrevistado em 2011, estranhou seu curso ser chamado de masculino: "Eu fiquei muito surpreso com esse rótulo de curso mais masculino". Sentindo-se provocado lembrou de mais uma professora que havia passado pelo Departamento de Física: "Não tão poucas assim, não foram só duas, tem mais uma, a professora $\mathrm{X}$ já foi professora deste departamento e hoje é do departamento de Matemática". Rememorou sua época de estudante e avaliou que a raridade de mulheres na Física vem diminuindo. Atribuiu-a "àquela coisa de se propagar no $2^{\circ}$ Grau [atual Ensino Médio] de que Física é difícil, Matemática é difícil... eu não sei se isso afasta as mulheres"; e também às famílias "que ficam orientando as filhas para que elas façam a área de [Ciências] Humanas, Letras, ou até Medicina".

Gráfico 1: Evolução de matrículas por sexo em Curso de Graduação em Física (1970-2017)

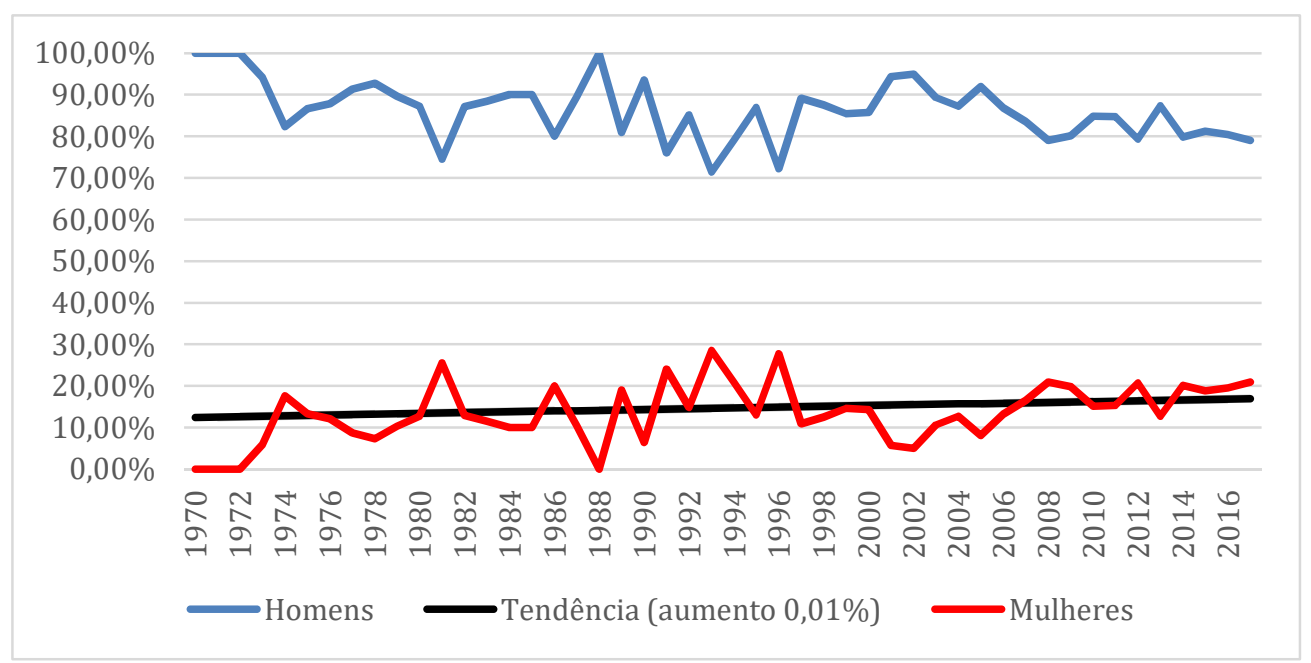

Fonte: Elaboração própria a partir de dados brutos fornecidos pela Superintendência de Tecnologia da Informação da IES.

O chefe de departamento, também entrevistado na ocasião, minimizou o problema e exaltou as raras mulheres que entram na Física:

Eu acho que não existe o preconceito contra mulheres não. $\mathrm{O}$ ambiente é que é mais masculino, mas eu nunca vi ninguém ser discriminada por ser mulher. Geralmente as mulheres quando fazem Física elas têm uma competência bem elevada. Então elas disputam de igual para igual e, às vezes, melhor do que um outro homem. 
Então hoje em dia essa relação já aumentou, você já encontra mais meninas fazendo. Agora, em outras áreas, tipo Química, já existe uma procura maior de mulheres, a Matemática... Muitas vezes a gente até discute porque a Física tem uma procura menor e a Matemática tem uma procura até maior, se você pensa que a Matemática é uma coisa muito mais abstrata do que a Física.

\section{Por que tão poucas?}

Esta pergunta vem sendo feita por estudiosas feministas de vários países. Hill, Corbett $e$ St. Rose (2010) argumentam que a resposta para a baixa participação das mulheres em CTEM está em fatores sociais e ambientais, e não em habilidades inatas, o que é evidenciado pelo rápido crescimento do número de alunas com altos escores em testes padronizados de Matemática nos Estados Unidos nas últimas décadas. No Brasil, Lombardi (2016), em um recente estado da arte sobre mulheres nas engenharias, aponta igualmente fatores culturais e educacionais.

Segundo Pierre Bourdieu (1999), as antigas estruturas da divisão sexual do trabalho perduram, apesar do sucesso escolar das meninas e mulheres, porque atuam através de três princípios práticos que associam a mulher às funções domésticas (ensino, cuidados, serviços) e subordinadas (ela não pode ter autoridade sobre homens) e, por outro lado, o homem aos objetos técnicos e às máquinas. Estes princípios correspondem tanto à segregação horizontal quanto à vertical do trabalho, ou seja, à raridade de mulheres na área de CTEM na maior parte dos países industrializados e ao teto de vidro, a não progressão delas a posições de alta remuneração, poder $e$ prestígio, e consequente subalternidade.

\section{Raridade}

Os fatores que inicialmente desviam as meninas das carreiras de CTEM são a socialização primária e secundária: a experiência familiar e sobretudo escolar, isto é, os/as professores/as, o ensino, o currículo, as relações com os pares (Roger; Duffield, 2000). O coordenador do curso de graduação em Física, citado acima, atribuiu o direcionamento das meninas às áreas de ciências humanas e da saúde à influência familiar. Mas o curso de Física forma os professores do ensino médio, que são em muito maior número do sexo masculino, e no currículo da formação docente a problemática de gênero está ausente.

É na escola, num aparente contexto de coeducação, que a experiência curricular vai gendrar as identidades e aspirações dos e das estudantes: as meninas não são estimuladas na matemática $e$ alguns professores têm expectativas mais baixas quanto ao desempenho delas (Warrington; Younger, 2000; Lima, 2013); assim, elas constroem sua suposta incompetência para as matérias ditas masculinas (Stepulevage, 2001), com base em crenças sobre a preponderância do talento inato sobre a aquisição de competências matemáticas e espaciais (Hill; Corbett; St. Rose, 2010); daí a baixa autoestima, autoconfiança e autoeficácia que marcam a socialização de gênero das mulheres e as levam a se autoexcluírem de carreiras não tradicionais (Donoso-Vázquez; Gazo; Moreno, 2013).

O primeiro "filtro de gênero" se dá na passagem do ensino médio ao superior, mas o "vazamento" continua ao longo da formação superior e pós-graduada e da inserção profissional (Blickenstaff, 2005), de forma que elas abandonam as carreiras científicas em número muito superior aos homens em todas as etapas e especialmente após o doutorado (Rees, 2001; Burger et al., 2010; Lacampagne et al., 2010). As razões apontadas são: falta de acesso a recursos; falta de conexão com as experiências vividas, de ênfase em aplicações concretas e contribuições sociais dos conteúdos curriculares; ambientes acadêmicos hostis; falta de senso de pertencimento a uma comunidade de prática; exclusão das redes sociais; e raridade de professoras nesses campos, sobretudo na pesquisa (Burger et al., 2010; Lacampagne et al., 2010).

Vejamos algumas experiências das sete alunas de Física, da graduação e pós-graduação, com idades entre 22 e 37 anos, entrevistadas por Amorim (2017) na mesma IES, em 2016.

Sobre a raridade de mulheres na Física, as respostas delas apontaram fatores internos/pessoais e externos/culturais associados à desigualdade de gênero. Uma aluna atribuiu ao 
"preconceito do próprio público feminino. Muitas mulheres se acham incapazes de fazerem um curso que envolve muitos cálculos e raciocínio lógico." Outras mencionaram o "machismo".

Sentimentos de exclusão, segregação e isolamento são experimentados pelas raras mulheres que entram na Física. A literatura internacional aponta o clima frio ou hostil, a ausência de empatia e receptividade encontrada pelas mulheres em suas tentativas de socialização entre colegas $e$ professores (Burger et al., 2010). Uma aluna lembrou com desgosto: "No começo era eu e meio mundo de macho escrotos, um ou outro que se salva [...] são segregadores ao extremo [...] eu tive poucos colegas que me trataram como igual." Vale ressaltar que um ambiente hostil a um indivíduo ou grupo, por gênero, raça ou outro motivo, não apenas é desfavorável a sua permanência, mas é adverso à formação de todos/as.

Persiste a imagem masculina do Físico, portanto, a mulher é vista como inadequada, sendo interrogada, confrontada e avaliada constantemente durante o curso (Barthelemey; McCormick; Henderson, 2016; Danielsson, 2012) e socialmente. Uma aluna confirmou isso: "A maioria das pessoas que me conhece diz: "Você é Física!? Você não parece Física'". E confessou que associava a Física à imagem de Einstein e se julgava distante dessa representação.

Segundo Sandler (2005), o sucesso das mulheres é atribuído à sorte ou à ação afirmativa, enquanto o dos homens é atribuído ao talento. Especialmente nos campos masculinos, elas carecem de credibilidade: têm suas competências continuamente testadas e precisam provar sua capacidade, o que abala sua autoconfiança e gera dúvidas e ansiedade sobre seu desempenho (Skibba, 2016; Rosa, 2013). Uma das alunas revelou sentir isso: "Sou cobrada para ser altamente eficiente enquanto aquele cara ali não é".

Em um ambiente masculino, a presença da mulher causa estranhamento e ela pode sofrer manifestações de violência simbólica, como piadas sexistas e assédio moral e sexual (Barthelemy; McCormick; Henderson, 2016). Uma aluna relatou: "Entrei de short na sala e o professor disse: 'Nossa, hein?' Aí eu fiquei toda sem graça e falei: 'Professor, o senhor está aqui para dar aula, não é para reparar no corpo de ninguém não"'. Esse tipo de situação, discriminatória e hostil para as mulheres, costuma ainda passar despercebida.

Em geral, as alunas entrevistadas por Amorim (2017) revelaram experiências constrangedoras, debilitantes e desafiantes em suas trajetórias - de fato, barreiras sexistas, naturalizadas na cultura acadêmica assim como na cultura mais ampla, que as excluem no contexto de sua inclusão e que só podem ser compreendidas da perspectiva de gênero. Para permanecer no curso de Física, as jovens mulheres têm de confrontá-las, superá-las ou minimizá-las. Houve uma aluna que disse que precisou fazer terapia para permanecer e concluir a graduação.

Embora vitoriosas, nem todas se dão conta da importância da consciência feminista para mudança de preconceitos como o da incompatibilidade entre as mulheres e a Física. Algumas alunas se ressentiam e reagiam confrontando professores e colegas. Uma aluna, considerada bonita, conseguiu se enturmar com os meninos. Outra foi objeto de estranhamento e suspeita de ser lésbica. Enfim, para permanecer no curso de Física as alunas precisaram superar estereótipos de gênero, preconceitos, discriminações e assédio, barreiras que se apresentam frequentemente invisibilizadas e naturalizadas.

\section{Subalternidade}

Quanto à segregação vertical, no desenvolvimento e progressão profissional o 'teto de vidro' constitui barreira tanto externa - socialmente imposta, quanto interna - internalizada pelas mulheres, que não ambicionam (e, se ambicionam, são impedidas de alcançarem) os postos de maior prestígio, responsabilidade e remuneração (Sarrió et al., 2002). Nesse contexto, destacam-se o medo da avaliação negativa como uma importante barreira psicológica, e a falta de modelos $e$ mentoras de sucesso que possam inspirar, oferecer oportunidades de aprendizagem compartilhada, apoio e proteção, bem como ensinar as regras do jogo (Donoso-Vazquez; Gazo; Moreno, 2013; Cooper, Eddy et al., 2010). Em campos onde elas estão em número muito reduzido, como a Física, a possibilidade de ter modelos e mentoras é quase nula.

Assim, devido à interação de fatores externos e internos, as carreiras acadêmicas das mulheres tenderiam a ser descontínuas (Shakeshaft et al., 2010), mais acanhadas ou menos 
brilhantes. Em todo caso, as condições de trabalho delas são desvantajosas e, ademais, sua vida diária é afetada pelo esforço de conciliação entre filhos/as e carreira, pela ansiedade diante da avaliação, fadiga e estresse (Acker; Armentib, 2004).

De acordo com Leonard (2001), o projeto iluminista da ciência e a profissionalidade acadêmica, na antiga forma e na nova forma gerencial, são gendrados; e a cultura das universidades é homossocial, radicada tanto num projeto de masculinidade, quanto num projeto heterossexual. $\mathrm{O}$ primeiro baseia-se na super racionalidade, cientificismo, independência $e$ antagonismo, no comportamento competitivo e autopromocional, negando ou excluindo elementos associados à feminilidade (o corpo, a emoção, as conexões pessoais e a aceitação da diversidade humana). O segundo propicia vantagens e privilégios aos homens ao excluir as mulheres das redes $e$ amizades masculinas $e$ das organizações formais, e/ou enquadrá-las na heterossociabilidade: como esposas de acadêmicos, colegas dóceis e diligentes em posições auxiliares, e objetos de assédio sexual.

As redes profissionais (que propiciam informação e visibilidade) são parte integral da trajetória acadêmica dos homens. Sendo a sociabilidade crucial para a inclusão, senso de pertencimento, aprendizado das normas tácitas e informais da academia e progresso na carreira, as mulheres em minoria na área de CTEM (diferentemente dos homens) não contam com redes de apoio de outras mulheres nas relações horizontais, nem com apoio de superiores e mentores do mesmo sexo nas relações verticais (Lacampagne et al., 2010; Öhrn et al., 2009; Leonard, 2001). Tampouco se incluem facilmente nas redes masculinas e ficam isoladas.

Vejamos como as trajetórias das três professoras, entrevistadas por Silva (2017), que passaram pelo Departamento de Física da IES pesquisado ilustram isso.

A Professora 1, entrevistada em 2011 e 2015, aos 57 e 62 anos, pode ser descrita como uma estrela que se apaga. Em 1977, aos 22 anos, sendo uma rara e brilhante aluna de Física, foi convidada a ingressar na carreira docente. Todavia, não vai se destacar a não ser pela dedicação ao ensino de graduação; não vai concorrer com seus colegas homens nem na pesquisa, nem na gestão; vai priorizar a família, os quatro filhos e o sucesso profissional do marido; e vai se aposentar sem concluir o doutorado, em 2003.

Ela expôs o desafio de conciliar docência, mestrado, casamento e maternidade:

Quando eu fiz Mestrado eu estava grávida do meu primeiro filho... Depois de dois anos veio outro. Foi um processo bastante complicado para mim, porque eu tinha que dividir as atividades de mãe, dona de casa, esposa e profissional [...] foi bastante cansativo.

O mestrado, concluiu 10 anos depois do ingresso na carreira, mas as tentativas de fazer o doutorado foram frustradas: o orientador de mestrado, com quem continuaria no doutorado, faleceu; outro possível orientador mudou-se do Brasil. Iniciou o doutorado em uma universidade próxima, sem afastamento nem redução de carga horária de aulas, mas se aposentou sem concluir. Ainda tentou retomar, mas novamente não pode concluir devido a problemas de saúde do pai e depois de um filho. Ficou trabalhando na educação a distância $(\mathrm{EaD})$ e ajudou o esposo, que também é Físico, a concluir o doutorado dele: sua tese envolveu uma experiência em EaD com professores do ensino de Ciências em que ele foi o professor e ela a tutora.

Em 1986 chegou ao Departamento de Física uma professora nova e promissora, com dois pós-doutorados, um deles na Alemanha, numa época em que eram raros os doutores no departamento. Ela chegou a coordenar o programa de pós-graduação de 1989 a 1991 e depois saiu da pós-graduação - disse que Física Nuclear, sua especialidade, saiu de moda. Não houve fatores externos/familiares que atrapalhassem seu desenvolvimento profissional - ela era casada, mas logo se divorciou e não teve filhos.

As entrevistas com a Professora 2 ocorreram em 2011 e 2015, quando tinha 63 anos. Ela demonstrou conhecimento e interesse pela problemática das relações de gênero na ciência:

Esse problema não é só brasileiro. É internacional e existem instituições preocupadas com isso, que promovem a participação da mulher na pesquisa em Física. Incentivam, criam bolsas específicas para mulheres. 
Lembrou que na sua graduação em Física, na USP, metade da turma era de mulheres e que teve muitas professoras.

A professora 2 se dedicou muito ao departamento:

Com relação à infraestrutura, condições de pesquisa, com relação a motivar as pessoas. [...] Eu já fui coordenadora da Biblioteca, quando ela era clandestina, já fui coordenadora do laboratório, quando ainda não existia laboratório, nós saímos do zero... e fui coordenadora da pós-graduação. Aí depois disso eu encerrei: 'eu não quero mais, é muito pesado [...] já dei a minha parte, agora deixa pra outros.

Contou que quando quis se dedicar à produção científica, se decepcionou "com o jeito como a Física está sendo feita", com as relações entre os pares nos eventos:

e aí eu comecei a me fechar um pouco. Eu me desinteressei desse jeito de fazer pesquisa. [...] Eu acho que não é só a Física, as outras áreas também estão sofrendo com essa questão da produtividade, é mais quantidade do que qualidade. [... Sentia falta da] vibração [...] em um workshop, antigamente, você ia trabalhar com todo mundo, cada um dava uma ideia, perguntas, respostas e ninguém queria mostrar que era melhor que o outro, a gente estava querendo descobrir alguma coisa nova [...] sem essa preocupação... esse tipo de coisa de 'macho' mesmo, de não mostrar que sabe menos.

Mesmo revelando-se crítica do androcentrismo da cultura científica, afirma que não se sentiu discriminada no departamento: "Como mulher eu nunca fui discriminada, nunca senti isso". Mas pontua dificuldades de convivência apesar de tentar se mimetizar:

os homens se sentem pouco à vontade... eu me sinto à vontade, mas quando eu percebo, já mudo de atitude. Por exemplo, eu não costumo me arrumar muito, para vir trabalhar, venho bem confortável, não sou muito feminina no cotidiano de trabalho, sou mais prática e objetiva. E o que muitas vezes eu enfrentei foi justamente desvalorização do meu trabalho por inveja, entende? [...] A gente sente uma grande desvalorização neste sentido, mas não é institucional.

Lembra que quando fazia o mestrado, foi encaminhada pelo orientador ao doutorado, concluindo tudo em quatro anos:

Eu fiz doutorado direto, coisa que nenhum macho fez naquela época, aí eles procuram desvalorizar, dizendo: 'ah, é porque tinham um caso, ela e o orientador' [...] porque uma mulher mostrar para o homem que ela é melhor do que ele, para eles, é muito difícil de engolir.

Nesse contexto de homossociabilidade e acirrada competição, sentiu-se vulnerável por ser mulher e optou por não entrar na briga por distinção acadêmica:

É uma área muito competitiva, eles brigam entre eles mesmos, eu fico observando, porque como mulher a gente não entra nessas brigas. Eu pelo menos não tenho vontade de entrar numa briga e de sair mostrando que eu sou melhor que os outros. Eu procuro fazer meu trabalho com amor, com prazer, que é o que eu gosto de fazer. Mas eles não, eles querem mostrar que o currículo deles é melhor que o do outro, já se encontraram no corredor trocando socos, um rasgando o trabalho do outro. É um negócio muito machista, é muito acirrada a competição, $e$, no meu caso, como eu também sou uma concorrente, o jeito mais fácil de acabar com essa concorrência é por esse lado, depreciando porque eu sou mulher. Então eles usam todas essas armas, para todos os lados. Eu sou vulnerável nesse aspecto.

Indagada sobre como era vista pelos colegas, respondeu: "Eles acham que eu sou uma pessoa que eles não precisam temer". Assim, não entrou na cultura de competição e exibicionismo do departamento e ficou à margem, onde se sentiu mais segura.

Eu me coloco numa posição um pouco afastada, como que observando o comportamento deles [...] não estou interessada em mostrar que sou melhor do que ninguém [...] eles são todos motivados para mostrar que são melhores, você vai numa reunião de departamento e você vê que eles se manifestam... vem outro e fala a mesma coisa, e eu fico vendo aquele exibicionismo 
desnecessário. O que eu noto é realmente essa competição entre eles e fico mais como observadora. Eu não tenho nenhum problema... Agora, se eu quisesse sair por aí mostrando que eu sou melhor que eles, aí eu sentiria alguma coisa. Eu costumo dizer o seguinte: que eles têm uma vida muito mais dura do que a nossa, porque eles têm que ser os melhores, eu não tenho que ser melhor em nada, não tenho que provar nada, mas eles não, eles sofrem muito.

Ao mesmo tempo, destaca que "o relacionamento pessoal com eles é ótimo, eu tenho colegas de muitos anos, que estão desde que eu entrei aqui e são meus amigos e a gente conversa normalmente, sem problema nenhum". Sobre a única colega mulher, diz que "de fato a gente não se vê, porque ela trabalha lá no laboratório, eu encontro com ela mais em programas culturais [fora da universidade] do que aqui".

Sobre as perspectivas de inclusão de outras docentes mulheres no Departamento de Física, não é otimista: "O problema é que tem muitos Físicos de alta capacidade no mercado e a maioria é homem, aí a chance é muito pequena de conseguir que a gente aumente a nossa porcentagem".

Enfim, a Professora 2, que tinha uma competência bem elevada e podia disputar não de igual para igual, mas acima dos homens do departamento (lembrando as palavras do chefe citado acima) colocou-se ou foi posta à margem da vida acadêmica, podendo ser considerada um talento desperdiçado. Ela se aposentou em 2017, no mesmo ano em que a Professora 3 se transferiu para outra IES, deixando o departamento sem nenhuma docente do sexo feminino.

A Professora 3 é estrangeira e ingressou no Departamento de Física como visitante, em 1995, junto com o marido brasileiro. Tinha doutorado na França e dois pós-doutorados, um no Brasil e outro nos EUA. Quando surgiu um concurso, o marido concorreu e foi aprovado. Em 1997 foi a vez dela fazer concurso, foi aprovada, mas não tomou posse porque questionaram a validade do seu diploma de doutorado que foi obtido no mesmo ano e universidade que o do marido. Só foi contratada em 1999 depois de entrar com recurso e ganhar:

E no final eu acabei entrando, o problema é que foram dois anos perdidos para a pesquisa, porque eu fiquei mais especialista na Constituição, nas leis do que na pesquisa. Eu não tinha tempo realmente de ler artigos, de trabalhar..

As entrevistas com a Professora 3 ocorreram em 2011 e 2015, quando ela tinha 50 anos. Ela tinha três filhos, duas meninas e um menino, a primeira nascida antes de ingressar como visitante, a outra filha $e$ o filho quando já era professora. Segundo ela, a maternidade

não interfere tanto, porque a gente tem essa sorte aqui no Brasil de ter a proximidade de casa $e$ essa possibilidade de ter alguém em casa para ajudar, apesar de a gente não ter família nenhuma aqui $e$ isso foi um pouquinho problemático. Atrapalhou um pouquinho, pontualmente, quando eles eram muito pequenos porque tem que cuidar mais. Mas deixei as crianças muito pequenas na creche o dia todo, tinha alguém em casa para ajudar e os horários são relativamente flexíveis na universidade, você não tem que bater ponto. Então, você trabalha quando pode, mas certamente isso diminui a sua disponibilidade. São três filhos e, com isso, certamente você não pode ser tão produtiva.

Declarou que o que mais gosta na carreira acadêmica é pesquisar e orientar. Considera "muito importante para os estudantes ter professores que são atuantes na pesquisa de ponta. Eu dou uma grande importância ao ensino, mas $80 \%$ do meu 'stress' é da pesquisa". Era líder de grupo de pesquisa, bolsista de Produtividade $\mathrm{CNPq}$, coordenadora de projeto financiado e de projeto Pibic, além de ser a primeira mulher a participar da área (minoritária) de Física Experimental no departamento. Todavia, não orientava nem ministrava disciplina na pósgraduação, contexto de constantes disputas políticas: "É exatamente um problema de homens, uma cultura masculina de brigas". Na graduação só dava aula de Física para as Engenharias. Ressalva que "tem mulheres que são realmente batalhadoras, eu não sou".

A Professora 3 revelou ter consciência de gênero e da homossociabilidade nas relações departamentais:

Você vê, aqui no Brasil, os homens vão falar com os homens, e é isso que a gente vê no departamento também. Inclusive, às vezes, é meio chocante, porque tem assuntos que dizem 
diretamente respeito a mim e alguém liga aqui e pede para falar com meu marido. Acontece que a minha situação é um pouquinho especial, porque meu marido trabalha comigo, então somos um casal, e mesmo quando o assunto diz respeito a mim tem gente que vai ligar para ele. $\mathrm{E}$ como eu não sou uma pessoa muito agressiva, eu não vou atrás, aí eu só faço observar.

Reconhece que os homens gozam de mais credibilidade e facilidades, graças à rede masculina na qual as mulheres, minoritárias e isoladas, não entram:

Dizer que não atrapalha ser mulher é realmente não querer ver o que acontece. Não tem obstáculos óbvios, é uma coisa mais sutil. Uma das coisas que eu não sei se atrapalha as mulheres, mas que mais ajuda aos homens é um tipo de rede que eles mantêm naturalmente, entre eles, e que a gente não tem. Bem, no Departamento de Física, são duas mulheres apenas, mas eu acho que é um problema geral, os homens são acostumados e rapidamente eles vão criar essa rede, e as mulheres não fazem isso. [...] No Departamento de Física, tem homem que chega aqui, um novo contratado, que não tem nem muita competência, não é agressivo nem nada, mas você vê que as coisas vão mais para ele do que iriam para mulheres, isso eu tenho certeza. Eu estou convencida, de maneira geral, que as mulheres têm que batalhar mais do que os homens para conseguir a mesma coisa. Como eu não sou batalhadora... e não tenho uma rede... Na questão de rede aqui só somos duas e inclusive não temos contato.

Como superar a situação de minoria sexual? A Professora 3 tem uma proposta política, mas sozinha, não tem como lutar por ela:

\begin{abstract}
Eu queria que tivesse realmente mais mulheres... Eu acho que as razões pelas quais tem mais homens do que mulheres não são genéticas, são realmente culturais. Teria que ter ações positivas no sentido de incentivar as meninas a irem para as carreiras científicas. Eu espero que as dificuldades se amenizem com o passar do tempo, mas elas não vão se amenizar sozinhas [...] eu acho que é mais um problema da sociedade. A gente já está melhor, eu já sou uma Física, eu sou suspeita... Acho que o problema está mais na família e na própria sociedade. Se tivesse possibilidade de formar um núcleo [de mulheres] na Física, mas aí teria que contratar mais mulheres, mas realmente eu concordaria em fazer uma coisa específica para mulheres, que seria uma discriminação positiva, no sentido de que tem que fazer mais para as mulheres do que para os homens, porque elas são mais discriminadas do que eles.
\end{abstract}

Pode-se supor que a Professora 3 se transferiu para outra IES porque não se sentiu incluída, ou satisfeita com as condições e o ambiente de trabalho, ou porque não visualizou oportunidades de desenvolvimento profissional promissoras, mesmo sendo um casal, situação que pode conferir um escudo à discriminação ou funcionar a favor quando se compartilham os encargos familiares $e$ se combinam as oportunidades dos dois.

\title{
Conclusão
}

Pode-se dizer que as mulheres que entram no curso de Física e depois na carreira docente correspondente são autosselecionadas e extraordinárias, considerando-se os filtros de gênero presentes na família, na escola e no curso superior, que afetam suas trajetórias. Embora não seja possível traçar um único perfil docente ou discente, é possível delinear um padrão de in(ex)clusão de mulheres na Física a partir de suas trajetórias em meio às práticas culturais vigentes.

As alunas entrevistadas explicitaram barreiras de gênero, implícitas e explícitas: o clima frio no curso, a imagem masculina do Físico, a falta de credibilidade das mulheres no campo, e a presença de preconceito e discriminação sexista e de assédio, muitas vezes naturalizados, entre colegas e professores.

As professoras, com histórias singulares em meio a circunstâncias diversas, com maior ou menor consciência de gênero, têm em comum a postura de acomodação, resistência e não confrontação, já que são não apenas minoria, mas isoladas no campo.

O conceito de gênero não é bem conhecido na IES pesquisada e não há ampla ou aguçada percepção, pelas docentes e discentes entrevistadas, da desigualdade ou discriminação de gênero nas relações acadêmicas, exceto nos casos das Professoras 2 e 3 . O mal estar, causado pela falta de 
reconhecimento e oportunidade, no caso das docentes, ou pelo descrédito e assédio moral ou sexual, no caso das discentes, nem sempre é visto como decorrente da injustiça de gênero.

A socialização/habitus feminino impõe expectativas específicas e autoexclusões às mulheres, inclusive às mais jovens, $e$ a hegemonia masculina na vida/cultura acadêmica se concretiza em limites tangíveis e sutis à valorização do desempenho acadêmico (das estudantes) e profissional (das professoras) e à progressão das mulheres nas ciências duras. Por outro lado, o habitus masculino do campo acadêmico influencia o comportamento delas, que se retraem, evitam conflitos, e até se vestem de forma a não chamar atenção. Elas vivem uma situação de invisibilidade (e descrédito) profissional como colegas e possíveis competidoras; e tratam de se manter invisíveis como mulheres para não se tornarem objeto de desejo ou assédio sexual, sobretudo as mais jovens/estudantes.

De modo geral, no contexto da pesquisa mais ampla (Carvalho, 2017), mulheres talentosas e bem-sucedidas situadas em departamentos masculinos, mesmo sendo objeto da eventual condescendência dos colegas, não se sentem inteiramente incluídas e se sentem parcialmente reconhecidas ou desvalorizadas. Elas assumem muito mais disciplinas básicas do que especializadas (e turmas maiores), muito mais ensino de graduação do que de pós-graduação, muito mais ensino do que pesquisa, e cargos de gestão só como coadjuvantes (sub, vice). Nem sempre percebem como as relações de gênero afetam suas trajetórias de carreira - a inclinação ao ensino, a postura não competitiva nas disputas departamentais, a não inclusão na pesquisa e na pós-graduação. Mesmo as docentes que tinham consciência de gênero optavam por não se desgastar e não lutavam por mudanças no jogo acadêmico, antevendo uma luta difícil e desigual.

A pesquisa - o impacto da entrevista, com suas idas e vindas - tem contribuído para visibilizar a problemática de gênero e provocar reflexões sobre os obstáculos internos (da cultura e práticas acadêmicas) e externos (da vida familiar) no desenvolvimento da carreira das docentes.

Porém é preciso ressaltar que não temos, nem no Brasil, nem na universidade pesquisada, políticas de equidade e paridade de gênero na formação superior e na inserção e desenvolvimento profissional. Uma primeira e importante iniciativa nessa direção foi o lançamento, em 2013, da chamada pública "Meninas e Jovens fazendo Ciências Exatas, Engenharias e Computação" (Nº 18/2013 MCTI/CNPq/SPM-PR/Petrobras), com o objetivo de ampliar o número de estudantes do sexo feminino nas carreiras de CTEM. Em 2018 foi lançada nova chamada. Seria interessante levantar quantos projetos desenvolvidos focaram/focam a Física.

Fica o desafio de incluir mulheres no curso, considerando que o baixo ingresso tem se mantido estável (conforme o gráfico apresentado para a IES estudada), bem como na carreira docente em departamentos onde elas estão ausentes ou são muito minoritárias, considerando que as ações afirmativas não têm sido contempladas (e têm sido até contestadas) entre nós.

Nesse sentido, é preciso visibilizar a lacuna das mulheres na Física (assim como em outros cursos da área de CTEM) e as barreiras por elas encontradas para ingresso e permanência, bem como visibilizar modelos de cientistas mulheres bem sucedidas. Também é preciso atentar e denunciar, continuamente, as práticas sexistas no cotidiano acadêmico, para que as mulheres não se sintam simbolicamente violentadas e excluídas. Sem dúvida, a inclusão de uma disciplina sobre "Gênero e Ciência" poderia ajudar no enfrentamento do problema, sem dispensar a necessária transversalidade de gênero no currículo.

Em conclusão, vale refletir sobre a afirmação de Londa Schienbinger (2001:40):

O ingresso de mais mulheres na ciência, a reforma das culturas da ciência, $e$ a abertura de novas questões para pesquisa dependem de instrumentos adequados de análise de gênero. Todos os três são problemas institucionais e intelectuais.

\section{Referências bibliográficas}

ACKER, Sandra; ARMENTIB, Carmen. Sleepless in academia. Gender and Education, v. 16, Issue 1, 2004, pp.3-24 [https://doi.org/10.1080/0954025032000170309 - acesso em: Jul.17 2015].

AGRELLO, Deise A.; GARG, Reva. Mulheres na física: poder e preconceito nos países em desenvolvimento. Revista Brasileira Ensino Física, v. 31, n.1, São Paulo, 2009, pp.1305.1-1305.6 [https://www.scielo.br/pdf/rbef/v31n1/v31n1a05.pdf - acesso em: Jul.17 2015]. 
ANDRADE, Sandra dos S. A entrevista narrativa ressignificada nas pesquisas educacionais pós-estruturalistas. In: MEYER, Dagmar E.; PARAÍSO, Marlucy A. (org). Metodologias de pesquisas pós-críticas em Educação. Belo Horizonte, Mazza Edições, 2012, pp.173-194.

AMORIM, Valquiria Gila de. Gênero e Educação Superior: Perspectivas de Alunas de Física. Dissertação (Mestrado em Educação), Universidade Federal da Paraíba, 2017.

BARTHELEMY, Ramón S.; MCCORMICK, Melinda; HENDERSON, Charles. Gender discrimination in physics and astronomy: Graduate student experiences of sexism and gender microaggressions. American $\begin{array}{llll}\text { Physics } \quad \text { Society, } & \text { Ridge, } & \text { NY, } & \end{array}$ [https://journals.aps.org/prper/abstract/10.1103/PhysRevPhysEducRes.12.020119 - acesso em: Jun.17 2017].

BLICKENSTAFF, Jacob Clark. Women and science careers: leaky pipeline or gender filter? Gender and Education, v. $\quad 17, \quad$ Issue $4, \quad 2005, \quad$ pp.369-386 [https://www.tandfonline.com/doi/abs/10.1080/09540250500145072 - acesso em: Jul.17 2015].

BOURDIEU, Pierre. A Dominação Masculina. Rio de Janeiro, Bertrand Brasil, 1999.

BURGER, Carol et alii. Gender equity in science, engineering, and technology. In: KLEIN, S. S. (gen. ed.). Handbook for Achieving Gender Equity Through Education. 2. ed. New York and London, Routledge, 2010, pp.255-279.

CARVALHO, Maria Eulina P. de. Relações de gênero em cursos masculinos: engenharias mecânica e civil, física, matemática e ciência da computação. Relatório de Pesquisa, Projeto 471892/2014-9, Chamada MCTI/CNPQ/MEC/CAPES nº 22/2014 - Ciências Humanas e Sociais. João Pessoa, Universidade Federal da Paraíba, 2017.

CARVALHO, Maria Eulina P. de. Relações de gênero na universidade: carreiras docentes e perspectivas profissionais discentes. Relatório de Pesquisa. Processo 401013/2010-3, Edital MCT/CNPq/MEC/CAPES $\mathrm{n}^{\circ}$ 02/2010 - Ciências Humanas, Sociais e Sociais Aplicadas. João Pessoa, Universidade Federal da Paraíba, 2012.

COOPER, Joanne et alii. Improving gender equity in post secondary education. In: KLEIN, S. S. (gen. ed.). Handbook for Achieving Gender Equity through Education, 2. ed., New York and London, Routledge, 2010, pp.631-653.

DANIELSSON, Anna T. Exploring woman university physics students "doing gender" and "doing physics". Gender and Education. v 24, n. 1, January, 2012, pp.25-39 [https:/www.tandfonline.com/doi/abs/10.1080/09540253.2011.565040 - acesso em: Jul.17 2015].

DONOSO-VAZQUEZ, Trinidad; GAZO, Pilar. F.; MORENO, Maria Luisa R. Factores discriminatorios en función del género en la carrera profesional de las mujeres. In: MONTANÉ, A; CARVALHO, M. E. P. de (coord.). Mujeres y Educación Superior. João Pessoa, Editora da UFPB, 2013, pp.55-74.

HILL, Catherine, CORBETT, Christianne; ST. ROSE, Andresse. Why so few? Women in Science, Technology, Engineering, and Mathematics. AAUW, Washington DC, 2010 [https://ww3.aauw.org/research/why-so-few/ - acesso em: Jul.17 2015].

KELCHTERMANS, Geert. Biographical methods in the study of teachers' professional development. In: CALGREN, Ingrid; HANDAL, Gunnar; VAAGE, Sveinung (ed.). Teacher thinking in action in varied contexts: research on teachers' thinking and practice. London, Falmer Press, 1994, pp.93-108.

LACAMPAGNE, Carole. B. et alii. Gender equity in mathematics. In: KLEIN, S. S. (gen. ed.). Handbook for Achieving Gender Equity Through Education. 2. ed. New York and London, Routledge, 2010, pp.235253.

LEONARD, Diana. A woman's guide to doctoral studies. Maidenhead, Open University Press, 2001.

LIMA, Nádia R. L. B. Quando as meninas não contam: gênero e ensino da matemática. Maceió, Viva Editora, 2013.

LOMBARDI, Maria Rosa (coord.). "Por que são tão poucas?": um estado da arte dos estudos em "Engenharia e gênero". Textos Fundação Carlos Chagas, Relatórios Técnicos (49), São Paulo, 2016, pp.1-48.

ÖHRN, Elisabet et alii. Gender and career in academia. Paper presented at the NERA Congress in Trondheim, Norway, March 5-7, 2009. 
REES, Teresa. Mainstreaming Gender Equality in Science in the European Union: The "ETAN Report". Gender and Education, v. 13, Issue 3, 2001, pp.243-260 [https://www.tandfonline.com/doi/abs/10.1080/09540250120063544 - acesso em: Jul.17 2015].

ROGER, Angela; DUFFIELD, Jill. Factors Underlying Persistent Gendered Option Choices in School Science and Technology in Scotland. Gender and Education, v. 12, Issue 3, 2000, pp.367-383 [https://www.tandfonline.com/doi/abs/10.1080/713668300 - acesso em: Jul.17 2015].

ROSA, Katemari D. da. Gender, Ethnicity, and Physics Education: Understanding How Black Women Build Their Identities as Scientists. Doctoral Dissertation, Science Education, Columbia University, 2013.

SANDLER, Bernice R. The Chilly Climate. National Association for Women in Education, 2005 [https://sun.iwu.edu/ mgardner/Articles/chillyclimate.pdf - acesso em: Nov.21 2015].

SARRIÓ, Maite et alii. El techo de cristal en la promoción profesional de las mujeres. Revista de Psicología Social, 17(2), 2002, pp.167-182 [https:/www.tandfonline.com/doi/abs/10.1174/021347402320007582 acesso em: Jul.17 2015].

SCHIEBINGER, Londa. O feminismo mudou a ciência?Bauru, EDUSC, 2001.

SHAKESHAFT, Charol et alii. Increasing gender equity in educational leadership. In: KLEIN, Susan S. (gen. ed.), Handbook for Achieving Gender Equity through Education, 2nd ed., New York and London, Routledge, 2010, pp.103-129.

SKIBBA, Ramin. Women in physics face big hurdles - still persistent biases continue to affect the numbers of female physicists. Natura/News, 2016 [http://www.nature.com/news/women-in-physics-face-big-hurdlesstill-1.20349 - acesso em: Jun 20 2016].

SILVA, Lucimeiry Batista da. Carreiras de professoras das Ciências Exatas e Engenharia: estudo em uma IFES do Nordeste brasileiro. Tese (Doutorado em Educação), Universidade Federal da Paraíba, 2017.

STEPULEVAGE, Linda. Gender/Technology Relations: Complicating the gender binary. Gender and Education, $\quad$ v. 13, Issue $3, \quad 2001, \quad$ pp.325-338 [https://www.tandfonline.com/doi/abs/10.1080/09540250120082525 - acesso em: Jul.17 2015].

WARRINGTON, Molly; YOUNGER, Michael. The Other Side of the Gender Gap. Gender and Education, v. 12, Issue 4, 2000, pp.493-508 [https://www.tandfonline.com/doi/abs/10.1080/09540250020004126 acesso em: Jul.17 2015]. 